\title{
Avaliação do pH e da eletrocondutividade do leite de bovinos da raça Jersey durante o primeiro mês de lactação ${ }^{1}$
}

\section{Evaluation of the pH and electrical conductivity in milk from jersey cows during the first month of lactation}

\author{
Raquel Fraga e Silva Raimondo ${ }^{2}$; Flavio Bracale Brandespim³; \\ Ana Paula Mazucco Prina ${ }^{3}$; Eduardo Harry Birgel Junior ${ }^{4}$
}

\begin{abstract}
Resumo
Com o objetivo de avaliar a influência do período colostral no $\mathrm{pH}$ e na eletrocondutividade foram colhidas 418 amostras de leite provenientes de mamas sadias de 127 vacas da raça Jersey e que não apresentem crescimento bacteriano no exame microbiológico. As amostras foram divididas em oito grupos a seguir discriminados: $<1 / 2$ dia; $1 / 2$ a $1^{\circ}$ dia; $2^{\circ}$ dia; $3^{\circ}$ dia; $4^{\circ}$ e $5^{\circ}$ dia; $6^{\circ}$ e $7^{\circ}$ dia; $8^{\circ}$ ao $15^{\circ}$ dia; $16^{\circ}$ ao $30^{\circ}$ dia em lactação.As amostras foram colhidas antes da ordenha, sendo as seguintes determinações realizadas: $\mathrm{pH}$ e eletrocondutividade. Durante a fase colostral o valor de $\mathrm{pH}$ aumentou até atingir os valores considerados normais para o leite enquanto o valor da eletrocondutividade diminuiu, sendo que a transição da secreção de colostro para leite ocorreu na primeira semana de lactação. Recomenda-se nas primeiras 24 horas de lactação (período colostral) a adoção dos seguintes limites de normalidade: $\mathrm{pH} \leq 6,51$ e eletrocondutividade $\leq 6,33 \mathrm{mS} / \mathrm{cm}$;. enquanto para o período entre o $2^{\circ}$ e $7^{\circ}$ dia de lactação (transição de colostro para leite) recomenda-se a adoção dos seguintes limites de normalidade: $\mathrm{pH} \leq 6,66$ e eletrocondutividade $\leq 5,93 \mathrm{mS} / \mathrm{cm}$.
\end{abstract}

Palavras-chave: Leite, $\mathrm{pH}$, eletrocondutividade, bovinos, raça Jersey

\begin{abstract}
In order to assess the influence of the colostrum period on $\mathrm{pH}$ and, electrical conductivity, we collected 418 milk samples from 127 Jersey cows. The samples were collected from healthy udders that did not present any bacterial growth in the microbiological examination. They were divided into eight groups as follows $<1 / 2$ day; $1 / 2$ and $1^{\circ}$ day; $2^{\circ}$ day; $3^{\circ}$ day; $4^{\circ}$ and $5^{\circ}$ day; $6^{\circ}$ and $7^{\circ}$ day; $8^{\circ}$ to $15^{\circ}$ day; $16^{\circ}$ to $30^{\circ}$ days of lactation. The samples were collected before milking and the following analyses were conducted: $\mathrm{pH}$, electrical conductivity. In the first 24 hours of lactation, there was an reduction in electrical conductivity value, associated with an increase in $\mathrm{pH}$ value. We observed that transition of secretion from colostrum to milk, occurs during the first week of lactation; from $6^{\text {rd }}$ day of lactation for $\mathrm{pH}$ value and $3^{\text {th }}$ day for electrical conductivity value. We recommend the use the following figures as normal ranges for the first 24 hours of lactation (colostrum period): $\mathrm{pH} \leq 6,51$ and electrical conductivity $\leq 6,33 \mathrm{mS} / \mathrm{cm}$; while for the interval between $2^{\text {nd }}$ and $7^{\text {th }}$ days of lactation (transition from colostrum to milk) we suggest the use of the values as normal ranges: $\mathrm{pH} \leq 6,66$ and electrical conductivity $\leq 5,93 \mathrm{mS} / \mathrm{cm}$.
\end{abstract}

Key words: Milk, pH, electrical conductivity, cattle, Jersey breed

1 Pesquisa realizada com auxílio financeiro da FAPESP processo $n^{\circ}$ 04/12049-5.

2 Bolsista de Mestrado da Fapesp Processo no 03/10224-1.

3 Centro de Pesquisa e Diagnóstico de Enfermidades de Ruminantes (CPDER) -Departamento de Clínica Médica da Faculdade de Medicina Veterinária e Zootecnia da USP.

4 Centro de Pesquisa e Diagnóstico de Enfermidades de Ruminantes (CPDER) -Departamento de Clínica Médica da Faculdade de Medicina Veterinária e Zootecnia da USP. São Paulo - SP. E-mail: ehbirgel@usp.br

* Autor para correspondência 


\section{Introdução}

Dentre os fatores responsáveis pelas alterações na composição e nas propriedades físico-químicas do leite merecem destaque aquelas decorrente das mamites que podem acometer bovinos em qualquer fase da lactação. No diagnóstico das mamites, o clínico veterinário, deve realizar, além do exame físico da glândula mamária, uma série de testes e provas complementares que avaliem a resposta inflamatória e ou a extensão da lesão provocada. Entre essas provas estão as determinações dos valores do $\mathrm{pH}$ e da eletrocondutividade na secreção láctea, pois a destruição do epitélio secretor, as alterações na permeabilidade vascular e o impedimento do transporte dos íons nas células danificadas observadas durante os processos inflamatórios na glândula mamária são responsáveis pelo aumento de íons de bicarbonato, determinando o aumento do $\mathrm{pH}$ do leite (SCHALM; CARROL; JAIN, 1971; BIRGEL, 2004; BIRGEL JUNIOR, 2006), bem como responsáveis pelo aumento das concentrações de sódio, cloro e bicarbonato, determinando um aumento nos valores da eletrocondutividade (KITCHEN, 1981; BIRGEL JUNIOR, 2006).

Pesquisas desenvolvidas no Departamento de Clínica Médica e no Centro dePesquisa e Diagnóstico de Enfermidades de Ruminantes (CPDER) do Departamento de Clínica Médica da Faculdade de Medicina Veterinária da Universidade de São Paulo (CUNHA, 1988; D'ANGELINO et al., 1988; ARAÚJO, 1994; ESTRELLA, 2001; BENATTI, 2001; MARQUES, 2003; BIRGEL JUNIOR, 2006) permitem afirmar que durante o período de lactação plena (entre 7 e 305 dias de lactação) os valores do $\mathrm{pH}$ variam entre 6,59 e 6,77 e da eletrocondutividade entre 5,10 e $5,59 \mathrm{mS} / \mathrm{cm}$. Apesar da contribuição das retro-mencionadas pesquisas terem permitido a avaliação da influência de diversos fatores, entre eles, a influência da fase da lactação (CUNHA, 1988; ARAÚJO, 1994; ESTRELLA, 2001; MARQUES, 2003; BIRGEL JUNIOR, 2006), do quarto mamário (ARAÚJO, 1994; ESTRELLA, 2001; MARQUES,
2003); da fase de ordenha (CUNHA, 1988), do tipo de exploração leiteira (ARAÚJO, 1994), da presença da infecção bacteriana (D'ANGELINO et al., 1988; ESTRELLA, 2001; BENATTI, 2001; MARQUES, 2003; BIRGEL JUNIOR, 2006) e da ocorrência da mamite (CUNHA, 1988; MARQUES, 2003; BIRGEL JUNIOR, 2006), ainda, não foram estabelecidos, de forma inquestionável, os padrões de referência para os diversos constituintes do leite de vacas sadias durante a fase colostral.

Ao se considerar a influência da fase colostral, na constituição físico-química do leite, observouse que nos primeiros dias de lactação ocorria um significativo aumento no valor de $\mathrm{pH}$ associados à diminuição do valor da eletrocondutividade (SCHALM; CARROL; JAIN, 1971; LINZELL; PEAKER, 1975; MAUNSELL et al., 1998a, 1998b; ESTRELLA, 2001; ONTSOUKA; BRUCKMAIER; BLUM, 2003; BIRGEL JUNIOR, 2006). Com a evolução da lactação, a secreção de colostro é gradativamente substituída pela secreção de leite sendo necessário à adoção de valores de referência, especialmente determinados para a primeira semana de lactação (BIRGEL JUNIOR, 2006).

A presente pesquisa teve a finalidade de avaliar os valores de $\mathrm{pH}$ e eletrocontudividade no primeiro mês de lactação, procurando estabelecer os valores de referência para a fase colostral e avaliar as alterações ocorridas nos 30 primeiros dias da lactação.

\section{Material e Métodos}

$\mathrm{Na}$ presente pesquisa foram utilizadas 418 amostras de leite provenientes de mamas sadias de 127 vacas da raça Jersey que não apresentaram isolamento e/ou crescimento bacteriano no exame microbiológico. As amostras de secreção láctea foram agrupadas em oito momentos de acordo com a fase de lactação em que se encontravam, conforme está discriminado na Tabela 1. 
Tabela 1. Constituição dos grupos experimentais para estabelecer o $\mathrm{pH}$ e a eletrocondutividade $(\mathrm{mS} / \mathrm{cm})$ na secreção láctea de bovinos da raça Jersey durante o primeiro mês de lactação

\begin{tabular}{ccccc}
\hline $\begin{array}{c}\text { Grupo } \\
\text { Experimental }\end{array}$ & \multicolumn{2}{c}{ Fase da Lactação } & $\begin{array}{c}\text { Número de } \\
\text { Quartos }\end{array}$ & $\begin{array}{c}\text { Número de } \\
\text { animais }\end{array}$ \\
\hline $\mathrm{A}$ & $<1 / 2 \mathrm{dia}$ & $0-12$ horas & 27 & 11 \\
$\mathrm{~B}$ & $1 / 2-11^{\circ} \mathrm{dia}$ & $12-24$ horas & 41 & 11 \\
$\mathrm{C}$ & $2^{\circ} \mathrm{dia}$ & $24-48$ horas & 47 & 15 \\
$\mathrm{D}$ & $3^{\circ} \mathrm{dia}$ & $48-72$ horas & 50 & 14 \\
$\mathrm{E}$ & $4^{\circ} \mathrm{e} 5^{\circ} \mathrm{dia}$ & $72-120$ horas & 86 & 25 \\
$\mathrm{~F}$ & $6^{\circ} \mathrm{e} 7^{\circ} \mathrm{dia}$ & $120-168$ horas & 48 & 13 \\
$\mathrm{G}$ & $8^{\circ}$ ao $15^{\circ} \mathrm{dia}$ & $168-360$ horas & 62 & 21 \\
$\mathrm{H}$ & $16^{\circ}$ ao $30^{\circ} \mathrm{dia}$ & $360-720$ horas & 57 & 17 \\
\hline \multicolumn{2}{c}{ Total de amostras } & $\mathbf{4 1 8}$ & $\mathbf{1 2 7}$ \\
\hline \multicolumn{4}{c}{}
\end{tabular}

O material utilizado foi colhido em três propriedades situadas no Estado de São Paulo, sendo as vacas mantidas em sistema de criação semi-extensivo no qual recebiam volumoso, com suplementação de silagem e concentrado comercial. Nas três propriedades adotava-se o sistema de ordenha mecânica, sendo antes da ordenha realizada a higiene do úbere por meio da imersão dos tetos em solução anti-séptica à base de cloro, em seguida secados com toalha de papel, ou realizada por um pano com solução anti-séptica. Após a ordenha, os tetos eram novamente imersos em uma solução antiséptica à base de iodophor.

As amostras utilizadas foram colhidas imediatamente antes da ordenha do animal, sendo a seleção dos animais empregados nessa pesquisa baseada no exame clínico dos animais e no histórico dos mesmos (BIRGEL, 2004), não sendo utilizadas amostras provenientes de animais que apresentaram episódios recorrentes de mamite, que no momento da colheita apresentaram alterações das características macroscópicas do leite ou perceptíveis durante a palpação da mama.

Após a anti-sepsia do orifício do teto, utilizando-se algodão embebido em álcool 70\%, foram desprezados os primeiros jatos de leite, para então realizar a colheita de cerca de $3 \mathrm{ml} \mathrm{de}$ leite, em frascos estéreis, os quais foram utilizados para o exame microbiológico. Em seguida, foram colhidas amostras para determinação dos valores do $\mathrm{pH}$ e eletrocondutividade em frascos de plástico descontaminados de íons, acondicionados em caixas de isopor e mantidos refrigerados até o momento do processamento, sendo os exames ( $\mathrm{pH}$, eletrocondutividade e microbiológico) realizados nos Laboratórios do Centro de Pesquisa e Diagnóstico de Enfermidades do Departamento de Clínica Médica da FMVZ-USP.

A determinação da concentração hidrogeniônica na secreção láctea foi realizada utilizando-se um medidor de pH modelo M20 da Digimed, calibrado para a temperatura ambiente e em soluções com $\mathrm{pH}$ 6,48 e $\mathrm{pH} 4,01$.

A determinação dos valores de eletrocondutividade foi efetuada, utilizando-se o aparelho Milku Mastitron, que mede a capacidade dos íons cloro, sódio e potássio existentes no leite de conduzirem corrente elétrica. Antes do início das determinações, o equipamento é calibrado com uma solução de cloreto de potássio a $0,1 \mathrm{~N}$, a $25^{\circ} \mathrm{C}$, e o valor lido no equipamento ajustado para 12,9 $\mathrm{mS} / \mathrm{cm}$. As amostras de leite foram depositadas diretamente no receptáculo do equipamento, em quantidade suficiente (aproximadamente $10 \mathrm{ml}$ ) para cobrir os eletrodos presentes no mesmo, permitindo a passagem de corrente elétrica, sendo a condutividade registrada, automaticamente, em um visor digital e o resultado expresso em $\mathrm{mS} / \mathrm{cm}$ (miliSiemens por $\mathrm{cm}$ ). 
As amostras de secreção láctea foram semeadas em Meio de Ágar-sangue e incubadas a $37^{\circ} \mathrm{C}$, sendo a avaliação para a identificação das bactérias realizadas com 24, 48 e 72 horas após a semeadura. Após 24 horas de incubação procedeuse à identificação dos gêneros das bactérias que apresentaram crescimento, sendo a identificação e diferenciação das espécies bacterianas realizadas segundo as recomendações de Lennette (1985) e Cowan e Steel (1985).

Os resultados foram apresentados em média, desvio padrão e intervalo de confiança, sendo que os dados foram primeiramente submetidos ao Teste de Levene para avaliar a homocedasticidade (homogeneidade de variâncias) entre os grupos experimentais. Verificou-se que as variáveis apresentavam, após a transformação logarítmica dos dados, homogeneidade na variância entre os grupos, permitindo que os dados fossem submetidos à análise de variância seguida da comparação dos pares de médias pelo método de Bonferroni (SCHEFFÉ, 1959; SAMPAIO, 1998).

\section{Resultados e Discussão}

A analise dos resultados apresentados na Figura 1 e Tabela 2 demonstrou que os valores do $\mathrm{pH}$ aumentaram gradativamente durante o primeiro mês de lactação.Em amostras colhidas com menos de 12 horas $(6,37 \pm 0,14)$ e colhidas entre 12 e 24 horas de lactação $(6,43 \pm 0,23)$ observou-se que os valores do $\mathrm{pH}$ eram significativamente mais ácidos do que os encontrados durante a fase de lactação plena. Esses resultados estão de acordo com aqueles obtidos por Schalm, Carrol e Jain (1971), Maunsell et al. (1998a, 1998b), Estrella (2001) e Birgel Junior (2006) que também relataram ser o valor do $\mathrm{pH}$ do colostro mais ácido do que o observado em outra fase da lactação. Segundo Santos e Rodrigues (1983) e Velloso (1998) a diferença do valor da acidez observada entre o colostro e o leite poderia ser facilmente explicada pelos maiores teores de sólidos totais e de proteína (total e fração da caseína) presentes na secreção colostral.

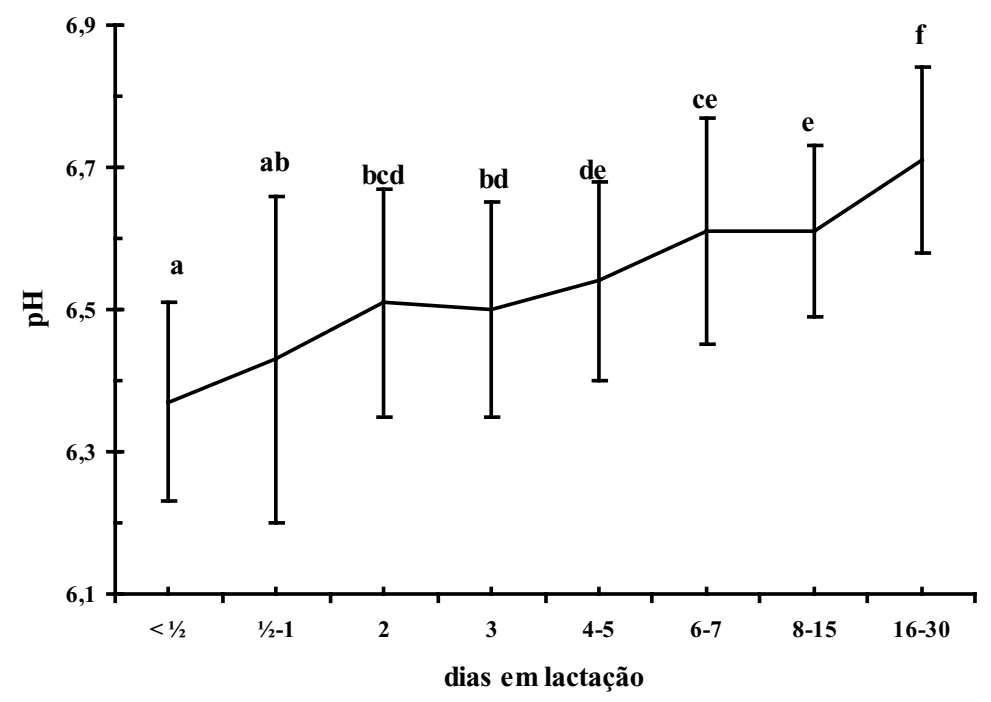

abcdef - letras diferentes significam diferença estatística entre os valores $(\mathrm{p} \leq 0,05)$ - teste de Bonferroni

Figura 1. Valores da concentração hidrogeniônica $(\mathrm{pH})$ na secreção láctea de bovinos da raça Jersey no primeiro mês de lactação. 
Tabela 2. Média, desvio padrão e intervalo de confiança* dos valores da concentração hidrogeniônica (pH) e da eletrocondutividade na secreção láctea de bovinos da raça Jersey no primeiro mês de lactação.

\begin{tabular}{|c|c|c|c|}
\hline \multirow{2}{*}{ Dias em Lactação } & \multirow{2}{*}{ Número de amostras } & \multicolumn{2}{|c|}{ Características Físico-Químicas } \\
\hline & & $\mathbf{p H}$ & $\begin{array}{c}\begin{array}{c}\text { Eletrocondutividade } \\
(\mathrm{mS} / \mathrm{cm})\end{array} \\
\end{array}$ \\
\hline $\begin{array}{c}<1 / 2 \text { dia } \\
\text { (0- } 12 \text { horas) }\end{array}$ & 27 & $\begin{array}{c}6,37 \pm 0,14 \mathbf{a} \\
(6,32-6,43)\end{array}$ & $\begin{array}{c}5,24 \pm 0,61 \mathbf{a b} \\
(5,01-5,49)\end{array}$ \\
\hline $\begin{array}{l}1 / 2-11^{\circ} \text { dia } \\
(12-24 \text { horas })\end{array}$ & 41 & $\begin{array}{c}6,43 \pm 0,23 \mathbf{a b} \\
(6,36-6,51)\end{array}$ & $\begin{array}{c}6,00 \pm 0,16 \mathbf{c} \\
(5,67-6,33)\end{array}$ \\
\hline $\begin{array}{c}2^{\circ} \text { dia } \\
(24-48 \text { horas })\end{array}$ & 47 & $\begin{array}{c}6,51 \pm 0,16 \text { bcd } \\
\quad(6,47-6,56)\end{array}$ & $\begin{array}{c}5,72 \pm 0,69 \mathbf{a c} \\
(5,52-5,93)\end{array}$ \\
\hline $\begin{array}{c}3^{\circ} \text { dia } \\
(48-72 \text { horas })\end{array}$ & 50 & $\begin{array}{c}6,50 \pm 0,15 \text { bd } \\
(6,46-6,54)\end{array}$ & $\begin{array}{c}5,51 \pm 0,76 \mathbf{a b} \\
(5,30-5,73)\end{array}$ \\
\hline $\begin{array}{c}4^{\circ} \text { e } 5^{\circ} \text { dia } \\
(72 \dashv 120 \text { horas })\end{array}$ & 86 & $\begin{array}{c}6,54 \pm 0,14 \text { de } \\
(6,51-6,57)\end{array}$ & $\begin{array}{c}5,12 \pm 0,66 \mathbf{b} \\
(4,98-5,27)\end{array}$ \\
\hline $\begin{array}{c}6^{\circ} \text { e } 7^{\circ} \text { dia } \\
(120-168 \text { horas })\end{array}$ & 48 & $\begin{array}{c}6,61 \pm 0,16 \text { ce } \\
(6,57-6,66)\end{array}$ & $\begin{array}{c}5,40 \pm 0,87 \mathbf{a b} \\
(5,14-5,66)\end{array}$ \\
\hline $\begin{array}{c}8^{\circ} \text { ao } 15^{\circ} \text { dia } \\
(168 \dashv-360 \text { horas })\end{array}$ & 62 & $\begin{array}{c}6,61 \pm 0,12 \mathbf{e} \\
(6,59-6,65)\end{array}$ & $\begin{array}{c}5,23 \pm 0,59 \mathbf{b} \\
(5,08-5,38)\end{array}$ \\
\hline $\begin{array}{c}16^{\circ} \text { ao } 30^{\circ} \text { dia } \\
(360-720 \text { horas })\end{array}$ & 57 & $\begin{array}{c}6,71 \pm 0,13 \mathbf{f} \\
(6,68-6,75)\end{array}$ & $\begin{array}{c}5,14 \pm 0,53 \mathbf{b} \\
(5,01-5,29)\end{array}$ \\
\hline
\end{tabular}

*_ _ intervalo no qual estão compreendidos $95 \%$ dos valores da população

abcdef - letras diferentes, na mesma coluna, significam diferença estatística entre os valores $(p \leq 0,05)$ - teste de Bonferroni ( ) - intervalo de confiança

Uma análise da literatura evidenciou que existe uma relativa concordância do momento em que ocorre a diminuição da acidez do leite, pois Mandsen et al. (2004) que consideraram como fase colostral amostras colhidas até o quinto dia de lactação, enquanto Estrella (2001) observou que esta condição havia desaparecido em amostras colhidas entre o quarto e sétimo dia de lactação e Birgel Junior (2006) em amostras colhidas entre o quinto e sétimo dia de lactação. Pelos resultados obtidos na presente pesquisa poderia afirmar-se que essa transição ocorreria na a partir do sexto dia de lactação, pois os valores observados no final da primeira semana em amostras colhidas no sexto e sétimo dia de lactação $(6,61 \pm 0,16)$ foram similares àqueles observados durante a lactação plena (entre 7 e 305 dias de lactação). A literatura compulsada demonstrou existir uma concordância entre os diversos autores brasileiros (CUNHA, 1988; ARAÚJO, 1994; ESTRELLA, 2001; MARQUES, 2003; BIRGEL JUNIOR, 2006) os valores de $\mathrm{pH}$ no leite de vacas sadias deveriam oscilar entre 6,59 e 6,77 .

Conforme pode ser observado na Figura 1 e Tabela 2 até o final do $30^{\circ}$ dia de lactação, os valores de $\mathrm{pH}$ continuaram a aumentar, sendo observado no grupo composto por amostras colhidas entre o $8^{\circ}$ e $15^{\circ}$ dia valores iguais a $6,61 \pm 0,12$ e no grupo composto por amostras colhidas entre o $15^{\circ}$ e $30^{\circ}$ dia de lactação valores iguais a $6,71 \pm 0,13$. Este aumento gradual dos valores do $\mathrm{pH}$ durante o primeiro mês de lactação já havia sido, anteriormente, descrito por Estrella (2001), porém estão em desacordo com 
as observações de Birgel Junior (2006) que não verificou, entre o $8^{\circ}$ e $30^{\circ}$ dia de lactação, variações nos valores do $\mathrm{pH}$.

Na Tabela 2 e Figura 2 observou-se que os valores da eletrocondutividade sofrem, no primeiro mês, influência de fatores relacionados à fase de lactação, em especial, durante o período no qual há secreção de colostro, sendo os valores máximos de eletrocondutividade observados nas amostras colhidas entre 12 e 24 horas $(6,00 \pm 0,16 \mathrm{mS} / \mathrm{cm})$ e no $2^{\circ}$ dia de lactação $(5,72 \pm 0,69 \mathrm{mS} / \mathrm{cm})$. Schalm, Carrol e Jain (1971), Linzell e Peaker (1975), Estrella (2001), Ontsouka, Bruckmaier e Blum (2003) e Birgel Junior (2006), também, haviam relatado que os valores de eletrocondutividade no colostro foram maiores do que os observados no leite de vacas em plena lactação. Segundo Linzell e Peaker (1975), o alto conteúdo mineral no colostro altera a composição iônica da secreção (PEAKER, 1975) e é responsável pela maior eletrocondutividade na secreção colostral, fazendo com que esses resultados fossem similares àqueles determinados no leite de vacas acometidas por mamites. Com o evoluir da lactação, após o final da fase colostral, verificou-se que os valores de eletrocondutividade encontrados permaneceram estáveis até o final do primeiro mês, oscilando entre $5,12 \pm 0,66 \mathrm{mS} / \mathrm{cm}$ e $5,51 \pm 0,76$ $\mathrm{mS} / \mathrm{cm}$ entre o $3^{\circ}$ e $30^{\circ}$ dia de lactação.

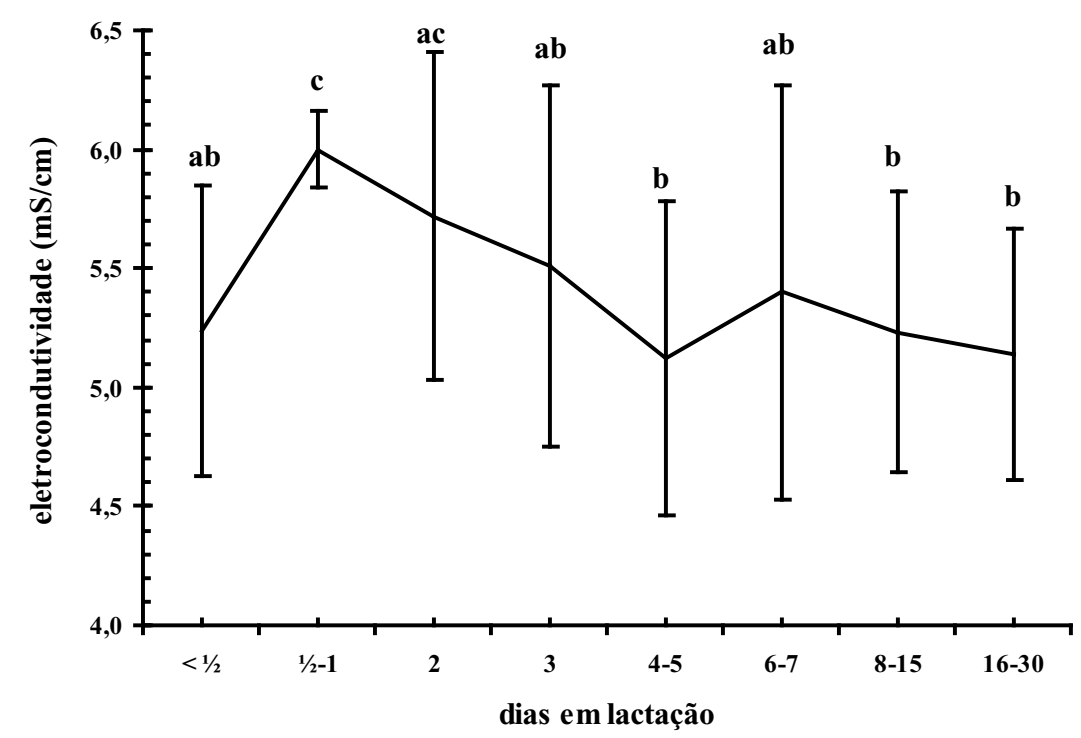

$a b c$ - letras diferentes significam diferença estatística entre os valores $(p \leq 0,05)$ - teste de Bonferroni

Figura 2. Valores de eletrocondutividade na secreção láctea de bovinos da raça Jersey no primeiro mês de lactação.

Complementando a análise dos resultados apresentados na Tabela 2 e Figura 2 merece ser destacado que os valores de eletrocondutividade obtidos nas primeiras 12 horas de lactação $(5,24 \pm$ $0,61 \mathrm{mS} / \mathrm{cm}$ ) foram significativamente menores do que os resultados esperados para esta fase da lactação. Uma possível explicação para este fenômeno poderia estar relacionada aos elevados teores lácteos de gordura do colostro que atuariam como obstáculo físico para a condução de eletricidade na secreção interferindo nos resultados obtidos (PRENTICE, 1962; FERNANDO; RINDSIG; SPAHR, 1981).

Uma análise da literatura evidenciou que não existe uma concordância do momento exato em que os valores de eletrocondutividade passam a ser similar aos observados durante a lactação plena, pois segundo Birgel Junior (2006) os valores da 
eletrocondutividade deixavam de sofrer influência da fase colostral a partir das amostras colhidas entre o $5^{\circ}$ e $7^{\circ}$ dia de lactação enquanto que para Estrella (2001) esta condição passa a ser observada a partir de amostras colhidas entre o $7^{\circ}$ e $15^{\circ}$ dia de lactação. Pelos resultados obtidos na presente pesquisa poderia afirmar-se que essa transição ocorreria na a partir do terceiro dia de lactação, pois os valores observados em amostras colhidas no quarto e quinto dia de lactação $(5,12 \pm 0,66 \mathrm{mS} / \mathrm{cm})$ foram similares àqueles observados durante a lactação plena (entre 7 e 305 dias de lactação). A literatura compulsada demonstrou existir uma concordância entre os diversos autores brasileiros (D'ANGELINO et al., 1988; ARAÚJO, 1994; ESTRELLA, 2001; BENATTI, 2001; MARQUES, 2003; BIRGEL JUNIOR, 2006) os valores de eletrocondutividade no leite de vacas sadias deveriam oscilar entre 5,10 e $5,59 \mathrm{mS} / \mathrm{cm}$.

As significativas modificações da constituição láctea observadas durante o período colostral tornam necessário que sejam adotados valores padrões de referência, especialmente determinados para a primeira semana de lactação, pois a utilização de valores de normalidade obtidos durante a lactação plena não permitem o diagnóstico correto dos processos inflamatórios da mama dos bovinos. Baseado na sua experiência profissional, Birgel (1982) afirmou que as mamites catarrais são a forma clínica de mamite mais frequentemente diagnostica nos bovinos (77,7 \% de todas as mamites), sendo que em 7,5\% desses casos o diagnóstico da enfermidade foi realizado durante a fase colostral.

$\mathrm{Na}$ fase colostral, considerando-se as 68 amostras de colostro sem isolamento bacteriano obtidas nas primeiras 24 horas após o parto ( $1^{\circ}$ dia de lactação) foram estabelecidos, baseados nos intervalos de confiança, os seguintes valores de referência: $\mathrm{pH}-$ entre 6,32 e 6,51 e Eletrocondutividade - entre 5,01 e $6,33 \mathrm{mS} / \mathrm{cm}$,
$\mathrm{Na}$ fase de transição do colostro para o leite, considerando-se as 231 amostras de secreção láctea sem crescimento bacteriano obtidas entre o $2^{\circ}$ e $7^{\circ o}$ dia de lactação devem ser adotados os seguintes valores de referencia: $\mathrm{pH}$ - entre 6,46 e 6,66 e Eletrocondutividade - entre 4,98 e 5,93 mS/cm,

Embora o objetivo desta pesquisa não fosse a apresentação de valores de referência para o período da lactação plena, verificou-se que não existe na literatura pesquisa na qual os valores de referência para o $\mathrm{pH}$ e eletrocondutividade do leite de bovinos da raça Jersey tenha sido estabelecida. Face a isso optou-se pela apresentação desses valores de referência, utilizando para tal finalidade os resultados obtidos no grupo composto por amostras de leite obtidas entre o $8^{\circ}$ e $30^{\circ}$ dia de lactação e que variaram, considerando o intervalo de confiança, entre 6,59 e 6,75 para o $\mathrm{pH}$ e entre 5,08 e $5,38 \mathrm{mS} /$ $\mathrm{cm}$ para a eletrocondutividade.

\section{Conclusões}

Durante a fase colostral ocorreu um significativo aumento no valor de $\mathrm{pH}$ e uma diminuição do valor da eletrocondutividade, sendo que a transição da secreção de colostro para leite em relação aos valores do $\mathrm{pH}$ de da eletrocondutividade ocorre na primeira semana de lactação, a partir do sexto dia de lactação para os valores de $\mathrm{pH}$ e a partir do terceiro dia de lactação para os valores de eletrocondutividade.

Recomenda-se nas primeiras 24 horas de lactação (período colostral) a adoção dos seguintes limites de normalidade: $\mathrm{pH} \leq 6,51$ e eletrocondutividade $\leq 6,33 \mathrm{mS} / \mathrm{cm}$; . enquanto para o período entre o $2^{\circ}$ e $7^{\circ}$ dia de lactação (transição de colostro para leite) recomenda-se a adoção dos seguintes limites de normalidade: $\mathrm{pH} \leq 6,66$ e eletrocondutividade $\leq$ $5,93 \mathrm{mS} / \mathrm{cm}$. 


\section{Referências}

ARAÚJO, W. P. Constituição físico-química, celular e microbiológica de leites tipo A, B e Especial colhidos de vacas criadas no estado de São Paulo: contribuição à semiologia da glândula mamária. 1994. Tese. (Livre Docência) - Faculdade de Medicina Veterinária e Zootecnia, Universidade de São Paulo, São Paulo.

BENATTI, L. A. T. Estudo comparativo entre o teste da eletrocondutividade e as provas fisico - químicas, microbiológicas e celulares do leite bovino. 2001. Dissertação (Mestrado em Clínica Veterinária) Faculdade de Medicina Veterinária e Zootecnia, Universidade de São Paulo, São Paulo.

BIRGEL JUNIOR, E. H. Características fisico-químicas, celulares e microbiológicas do leite de bovinos das raças Holandesa, Gir e Girolando criados no Estado de São Paulo. 2006. Tese. (Livre Docência) - Faculdade de Medicina Veterinária e Zootecnia, Universidade de São Paulo, São Paulo.

BIRGEL, E. H. Avaliação das provas utilizadas no diagnóstico da mamite bovina. In: BIRGEL, E. H.; BENESI, F. J. Patologia clínica veterinária. São Paulo: Sociedade Paulista de Medicina Veterinária, 1982. p. 177-213.

BIRGEL, E. H. Semiologia da glândula mamária de ruminantes. In: FEITOSA, F. L. Semiologia veterinária: a arte do diagnóstico. São Paulo: Roca, 2004. p. 353399.

COWAN, S.; STEEL,K. J. Cowan and steel's manual for identification of medical bacteria. 2.ed. Cambridge: University Press, 1985.

CUNHA, M. S. Contribuição ao diagnóstico clínico das mastites. Influência das fase da lactação, fases da ordenha e dos processos inflamatórios na composição fisico-química, celular e microbiológica do leite de vacas da raça holandesa preta e branca. 1988. Dissertação. (Mestrado em Clínica Veterinária) - Faculdade de Medicina Veterinária e Zootecnia, Universidade de São Paulo, São Paulo.

D'ANGELINO, J. L.; BIRGEL, E. H.; CUNHA, M. S.; FUGIMOTO, S. Estudo comparativo do Milk Checker em relação aos parâmentros físico-químicos, citológicos e microbiológicos do leite In: CONGRESSO BRASILEIRO DE MEDICINA VETERINÁRIA, 21., 1988, Salvador. Anais... Salvador: SBMV, 1988. p. 235.

ESTRELLA, S. L. G. Características físico-químicas e celulares do leite de bovinos da raça holandesa, criados no estado de São Paulo: Influência da fase da lactação, dos quartos mamários, do número de lactações e do isolamento bacteriano. 2001. Dissertação. (Mestrado em Clínica Veterinária) - Faculdade de Medicina Veterinária e Zootecnia, Universidade de São Paulo, São Paulo.

FERNANDO, R. S.; RINDSIG, R. B.; SPAHR, S. L. Effect of length of milk interval and fat content on milk conductivity and its use for detecting mastitis. Journal of Dairy Science, Champaign, v. 64, n. 4, p. 678-682, 1981.

KITCHEN, B. J. Review of the progress of dairy science: bovine mastitis: milk compositional changes and related diagnosis test. Journal of Dairy Research, Cambridge, v. 48, n. 2, p. 167-188, 1981.

LENNETTE, E.H.(Ed.). Manual of clinicalmicrobiology. 4.ed. Washington: American Society for Microbiology, 1985.

LINZELL, J. L.; PEAKER, M. Efficacy of the measurement of the electrical conductivity of milk for the detection of subclinical mastitis in cows: detection of infected cows at a single visit. British Veterinary Journal, London, v. 131, n. 4, p. 447-461, 1975.

MANDSEN, B. D.; RASMUSSEN, M. D.; NIELSEN, M. O.; WIKING, L.; LARSEN L. B. Physical properties of mammary secretions in relation to chemical changes during transition from colostrums to milk. Journal of Dairy Research, Cambridge, v. 71 , n. 3, p. 263-272, 2004.

MARQUES, R. S. Avaliação das características físicoquímicas e celulares do leite de bovinos da raça Girolando criados no Estado de São Paulo. 2003. Dissertação. (Mestrado em Clínica Veterinária) - Faculdade de Medicina Veterinária e Zootecnia, Universidade de São Paulo, São Paulo.

MAUNSELL, F.; MORIN, D.; CONSTABLE, P.; HURLEY, W. Mastitis indices and colostral quality in uninfected mammary glands. In: ANNUAL MEETING OF NATIONAL MASTITIS COUNCIL, 37., 1998, Saint Louis. Proceedings... Madison: N.M.C, 1998b. p. 303304.

MAUNSELL, F.; MORIN, D.; CONSTABLE, P.; HURLEY, W.; McCOY, G. C.; KAKOMA, I.; ISAACSON, R. E. Effects of mastitis on the volume and composition of colostrums produced by holstein cows. Journal of Dairy Science, Champaign, v. 81, n. 5, p. 1291-1299, 1998a.

ONTSOUKA, C. E.; BRUCKMAIER, R. M.; BLUM, J. W. Fractionized milk composition during removal of colostrum and mature milk. Journal of Dairy Science, Champaign, v. 86, n. 6, p. 2005-2011, 2003. 
PEAKER, M. Recent advances in the study of monovalente ion movements across the mammary epithelium: Relation to onset of lactation. Journal of Dairy Science, Champaign, v. 58, n. 6, p. 1042-1047, 1975.

PRENTICE, H. J. The conductivity of milk - effect of the volume and the degree of dispersion of fat. Journal of Dairy Research, Cambridge, v. 29, n. 1, p. 131-139, 1962.

SAMPAIO, I. B. M. Estatística aplicada à experimentação animal. Belo Horizonte: Fundação de Ensino e Pesquisa em Medicina Veterinária e Zootecnia, 1998.
SANTOS, E. C.; RODRIGUES, R. Acidez do leite. Revista do Instituto de Laticínios Cândido Tostes, Juiz de Fora, v. 38, n. 230, p. 9-17, 1983.

SCHALM, O. W.; CARROLL, E. J.; JAIN, N. C. Bovine mastitis. Philadelphia: Lea \& Febiger, 1971.

SCHEFFÉ, H. The analysis of variance. New York: John Wiley, 1959.

VELLOSO, C. R. V. Noções básicas de acidez. In: BRITO, J. R. F. A qualidade do leite. Juiz de Fora: Embrapa, 1998. p. 91-98. 
